\title{
The Challenge of Nonconfrontational Ethics
}

\author{
JOHN HARRIS
}

\section{The Argument}

Matti Häyry's new book is deliberately challenging; it tells six contemporary bioethicists, and all who share their methodologies or even their general approach, that they have got it badly wrong. From the striking photograph of Häyry himself on the front cover to the very last line, the genetic challenge is issued and elaborated. Häyry has divided his protagonists into three pairs, of which I find myself a member, and this makes responding a duty as well as a pleasure. Although I cannot speak for my partner in crime, Jonathan Glover, I am at least in the very best of all possible company.

Häyry's book is self-consciously a work on methodology in bioethics. John Coggon has exposed many of the weaknesses of Häyry's methodological approach, ${ }^{1}$ and because I cannot usefully add to these, I believe, decisive objections to Häyry's overall approach, I want to take up two themes that are not prominent in Coggon's analysis.

\section{Nonconfrontational Ethics}

A key element in Häyry's approach is that he recommends and espouses a "nonconfrontational" notion of rationality that he believes is the key to the best methodological approach to the ethical problems posed by genetics. My first problem is that I do not see much merit in a nonconfrontational approach to the resolution of ethical problems. This may be a matter of personality as much as methodology; I happen to enjoy a good argument, both in the sense of appreciating a convincing set of reasons for believing or doing something and because I also enjoy a frank exchange of views and often find the exchange illuminating as well as satisfying. However, I also think there are good reasons to believe that the ideal of avoiding confrontation involves commitment to a dysfunctional sort of political correctness and one which is rarely productive of clear thinking or concise argument. Evil and wickedness need to be confronted, and even apparently milder forms of error in matters ethical can matter hugely for the very reasons that make them ethical issues. I am fond of the idea that if morality is the science of the good, then ethics is the study of that science. If this is right, then we see clear reasons for, and justification of, confrontation. As in anything that is, in principle, demonstrable, it is important to try to arrive at the truth or, more modestly, at the most satisfying explanation of the way the world

I am grateful for helpful comments from John Coggon, Sarah Chan, Simona Giordano, and Rebecca Bennett. I acknowledge with gratitude the stimulus and support of the iSEI Wellcome Programme in the Human Body, its Scope, Limits, and Future. 


\section{The Challenge of Nonconfrontational Ethics}

is or the most effective strategy for achieving one's goals. The best course of action in ethics is often demonstrable, and part of this demonstration can involve revealing as conclusively as possible the errors in, or problems that beset, alternative views.

However, confrontation is not necessarily hostile, even though people often take offense when others try to point out the error of their ways or the mistakes in their reasoning. Philosophy is essentially, and indeed etymologically, a love of knowledge or wisdom. As the Oxford English Dictionary suggests in the first definition of philosophy: " 1 . (In the original and widest sense.) The love, study or pursuit of wisdom, or of knowledge of things and their causes, whether theoretical or practical. ${ }^{2}$

Falsehood or bad argument is not loved or indeed pursued amorously by philosophers; quite the reverse! That is not just how it is, but how it should be. In science, error can cost not only time and money but also lives, and the same is true in ethics, and particularly in what Häyry calls "genethics." Ethical conclusions are, like those of science, also very often, as I have suggested, demonstrable in that a combination of evidence and argument can prove conclusive in their articulation and acceptance. Certain conclusions in ethics unequivocally recommend themselves to reason, not least because there is often an overwhelming agreement about the ends to be achieved (saving lives, minimizing suffering, making the world a better place), and the best means to realize these are also often obvious and compelling. To take some clear examples, once effective and safe vaccines for smallpox and polio had been developed the conclusion of the practical syllogism was obvious: disseminate them as widely and as speedily as possible. This is true for all established connections between threats to life and safe ${ }^{3}$ means of neutralizing or minimizing those threats. The connection between diet, exercise, and heart disease, between smoking and lung cancer, and between some genes and illness are all examples of such connections that indicate safe preventive strategies.

Häyry lists seven ways of making people better and discusses ethical approaches to the legitimacy of utilizing these ways. But to fail to make people better when we can is necessarily to leave them worse, or worse off, than they need be; sometimes this means that they are fatally worse off. This matters! Of course, where individuals do not want to be protected from harm or have their conditions or circumstances ameliorated, this is absolutely a matter for them. I believe, however, that there are the strongest moral reasons to persuade, and where necessary confront, the views and the individuals who stand between people and what often is their only chance to have a better life or make their lives better.

To confront, with evidence and argument, the views of others should not and need not be hostile or offensive. Philosophers, and indeed all people of good will, should welcome criticism of their research and their views and be happy to engage in the discussion that alone can lead to better research and better conclusions, even where that discussion is conducted vigorously. Engagement, moral, political, and theoretical, may involve confrontation, but I would suggest it is no worse for that. The alternative is not necessarily more reasonable or more rational, or more civilized, and it may be less committed, less open, and less honest.

In the last chapter of Häyry's book, which he calls tellingly, "Taking the Genetic Challenge Rationally," he strongly implies that this is what his methodology is doing and has done throughout, with the implication that some of those who do 
not accept his methodology are not taking the genetic challenge rationally. It is somewhat ironic, then, that Häyry continuously castigates me in the book for allegedly tending "to see opposing views as irrational." ${ }^{4}$ Indeed, Häyry lists this tendency of mine as the second main problem with my entire approach. ${ }^{5}$ It is perhaps also of some psychological interest that Häyry regards castigating me for valuing and using rationality as an example of nonconfrontational ethics!

In his last section to this chapter Häyry writes of his book that it

provides all the normative guidance that books on philosophical ethics can. It presents the main arguments for and against genetic and related techniques and practices, with commentaries on their strengths and weaknesses. Intelligent readers can, in the light of these, articulate their own views on the activities involved and make their own moral judgements concerning them. Secondly the book refuses to claim absolute validity for particular norms on philosophical grounds. Philosophical considerations can show that some arguments are flawed and others open to discussion, but they cannot prove to everybody's satisfaction the rightness or wrongness of selection, cloning, or new treatments. The practical point of the book, then, is to empower readers to make up their own minds on genetic and related technologies, and not to lull themselves into thinking that they can find ready-made answers of universal validity in philosophical writings. ${ }^{6}$

We will come in a moment to Häyry's first claim about the reliability of his presentation of the arguments of others. His second claim: "Intelligent readers can, in the light of these, articulate their own views on the activities involved and make their own moral judgements concerning them" goes of course also for all intelligent readers of any book whatsoever; no difference between us there. Even Häyry cannot subvert the intelligence of his readers and neither can I. Nor does either of us, I am sure, want or intend to do any such thing. Häyry claims another virtue for his book: "the book refuses to claim absolute validity for particular norms on philosophical grounds." The implication is again that others, probably those he takes as his protagonists, do make absolute claims. At the risk of seeming confrontational I am bound to say: "big deal!" Neither I nor, I am sure, any of the other authors on whose judgments and methodologies Häyry provides "commentaries on their strengths and weaknesses" would claim anything so stupid. So that there can be no ambiguity, I have never claimed absolute validity for anything. What I do often claim on the basis of the evidence and argument I adduce is that there are good reasons to accept the conclusions to which I or others come. If there are not, neither I nor anyone would have any business coming to any conclusions at all. Even Häyry has been known to come to a conclusion or two, and when he does I assume he believes it is on some rational basis. This, I suggest, must mean that his conclusions recommend themselves to reason more powerfully than alternatives, that is, they are more rational than (and ipso facto confrontational of) less plausible views. To the extent that they are overwhelmingly persuasive, they will become as "objective" as are scientific theories or facts that have attained the same degree of persuasiveness.

\section{Evidence and Argument}

A second problem I have is with elements of Häyry's methodology that he does not highlight as of methodological interest at all. I would like to suggest two 
essential elements to any adequate methodology in bioethics or indeed in any other field. One is to represent those whose work you criticize, if not objectively, at least accurately. Every decent academic tries to do this, and I am sure Häyry believes he has also done so. The second is to demonstrate this accuracy by allowing your opponents to speak in their own voice, and to do this it is necessary to quote chapter and verse and to accurately reference the quotations. By this I mean it is necessary to quote at sufficient length for it to be obvious to the reader that your protagonist has actually said what you say she has said. This methodological safeguard protects us all, as far as it is possible so to do, against the charge of misrepresentation.

Häyry, however, does not often let his protagonists speak in their own voice or their own words. Rather he chooses to offer characterizations of the positions he believes we hold in his own words and even sometimes tells his protagonists off when their views do not quite match his caricatures of them! ${ }^{7}$

Thus, when he criticizes me and others, he often puts our thoughts into his own words, neither citing works nor usually giving page references to where our alleged statements are to be found. ${ }^{8}$ He also sometimes goes further! On page 157 of his book he says, "The idea Harris suggests, and especially its application to ova harvesting, can be challenged from at least three angles." He then rather lamely adds in a footnote, "Harris does not discuss this in his paper, so some of the criticisms are to Harris-like rather than actually Harris-related views." Readers can judge the effectiveness as well as the respectability of a methodological device like this.

This demonstrates the literally fiendish cunning of the Matti Häyry methodology. He has sprung his trap and even that other great professorial " $M$ " of diabolical stratagems, the incomparable Professor Moriarty himself, could not have secured a more complete victory. For in attributing to me, for example, positions that I do not hold, have never held, and for which he provides no evidence in the form of quotations or citations, he invites me to show where and when I did not in fact say the things attributed to me. But if you ask me where and when I do not say these things I would have to answer, rather lamely, that I always do not say them and I do not say them everywhere! References for my denial would have to be to every page of every book and paper that I have written.

Another key methodological device Häyry adopts is to choose a label for the philosophical positions of his opponents and then, having set out the defining characteristics of the position to which he attaches the label, he proceeds to find fault with us for departing from his conception of the position he thinks we ought to hold. This is of course a highly effective methodology! ${ }^{10}$

\section{The Evidence}

Because I appear throughout Häyry's book, this paper might have turned out to be very long indeed. To avoid this disaster, I am being selective. I take just one set of examples from Chapter 2, not least because they are characteristic of problems with his methodological approach. Of course there are also many places where Häyry does me justice, and even more than justice, and for these I am grateful. 
John Harris

\section{Example 1}

This occurs in Chapter 2 and I start at page 29. I adopt the practice of setting out Häyry's claims in full by direct quotation and then answering them.

According to Glover and Harris, then, one fundamental reason against killing people and failing to save their lives is that these choices would eliminate the worthwhile future existence of a currently existing person. Similar reasons can be extended to reproductive choices. Failure to conceive and a decision to terminate a pregnancy would also eliminate the future existence of a person, albeit a currently nonexistent one. Therefore the view stipulates that it would be wrong not to bring about a life worth living or of value, provided that the life is qualitatively so good that it does not lower the average goodness of the lives of the population as a whole. ${ }^{11}$

This section is footnoted as follows: "Glover 1977, pp. 69-70, 140; cf. Harris, 1992, pp. 176-7."

I shall not comment on whether the attributions to Jonathan Glover are correct. $\mathrm{He}$ is well able to defend himself. The citation "Harris, 1992" is to my book Wonderwoman and Superman. ${ }^{12}$ However, neither on the pages cited nor anywhere else do I say anything remotely like this, not least because I do not think anything remotely like this.

Indeed so far from it being true that "according to . . . Harris, then, one fundamental reason against killing people and failing to save their lives is that these choices would eliminate the worthwhile future existence of a currently existing person," I am on record as both denying this and saying something fundamentally different, not least because I believe that the entitlement of an existing person to experience the future is not dependent upon the worthwhile nature of that future. People are entitled to live even lives that are not worthwhile (either on their own judgment or on that of anyone else) if they want to.

On the very page that Häyry cites (page 177 of Wonderwoman and Superman) on the contrary I say:

However the wrong of all presently existing individuals, say, simply deciding not to reproduce, simply deciding that the present generation should be the last, is of a different order. It is different because it would not involve violating the will to live of any person, nor the destruction of the ecosystem. Indeed there is a sense in which it might be better for the ecosystem as a whole if this were to happen-better in the sense that the system (humans apart) would be less in danger of total destruction. . . . However, it would I think be wrong for two distinct and important reasons. The first is that it would be to prefer a universe with less happiness and less satisfaction of desires than the alternative in which persons did continue to exist, and secondly because it might involve the permanent end of the only creatures anywhere who have both these capacities.

Note that I do not say anything to imply objection to the elimination of the worthwhile "future existence of a currently existing person." Nor do I say anything about the elimination of "the future existence of a person, albeit a currently nonexistent one" whatever that may mean! (How can you eliminate a nonexistent person either now or in the future?) The pages Häyry cites are not about decisions adversely affecting existing people at all. My thoughts on the pages Häyry cites are about possible worlds scenarios, they are about what sorts 


\section{The Challenge of Nonconfrontational Ethics}

of people there should be in the future and whether there are good moral arguments to ensure that there will be future people at all. Nothing I say or believe about the ethics of such scenarios involves at any stage or in any way deployment of or even consideration of a "fundamental reason against killing people and failing to save their lives," which turns on the fact that "these choices would eliminate the worthwhile future existence of a currently existing person."

Indeed in my most recent book I point out that so-called future of value arguments, such as those Häyry attributes to me, are just forms of the potentiality argument, a form of argument I have consistently rejected in print since $1985 .{ }^{13} \mathrm{I}$ will not discuss here the question of whether it is confrontational or not to attribute views one wishes to attack to someone when there is no basis for believing he holds them.

Häyry has placed me in the position in which Sir Arthur Streeb-Greebling found himself in a radio interview with Dudley Moore, when questioned about his groundbreaking (or rather wave-breaking) work as a naturalist. Sir Arthur was forced into a confrontational stance. Moore asked him: "Where did you strat your work?" Sir Arthur's response is legendary:

I think it can be said of me that I have never, ever strated my work. That is one thing I have never done. I can lay my hand on my heart, or indeed on anyone else's heart, and say I have never strated my work, never strated at all. I think what you probably wanted to know is when I started my work. $^{14}$

\section{Example 2}

Put in terms of worth, Glover and Harris postulate three categories of lives: those more worth living, those less worth living; and those not worth living. ${ }^{15}$

No reference is given to the claim that I postulate this. Of course, it is evidently true that some lives are better than others. I myself envy the lives (and indeed the lifestyles) of many other people. Some lives are more worth living, some less, and some, a few, are truly not worth living, and I have certainly said that there are some lives that are definitely worth "not living." But the way that Häyry puts this point seems to imply that I believe there exist three classes of individuals who have lives of ascending or descending value in the sense that those with lives more worth living are people who matter more, have lives that are more worth saving, or have more civil, political, or moral rights and so on than those with less valuable lives. When I say "I wish I could still play squash and envy those who can," I am not implying that I am in a morally "different category" to those who can play squash. What Häyry seems to attribute to me I certainly do not believe, and I have never said anything that could imply such a division of living persons into lives of different value in the sense of lives of different moral worth or lives that are more or less worth saving than those of others.

My concept of personhood, outlined in my book The Value of Life, and repeatedly since, $^{16}$ is clearly set out as, and explicitly stated to entail, that personhood is a threshold concept and that once over the threshold all people have the same moral status. I have repeatedly stated that this applies to all existing persons regardless of quality of life, life expectancy, race, religion, nationality, level of 
disability, and much more besides! Moreover the threshold is a very low one, so that all self-conscious human beings, however disabled and regardless of quality of life, will qualify. This will include all infants at some point, probably ${ }^{17}$ in the first six months of life, and all adults, save those who have permanently lost consciousness, for example, those in a permanent vegetative state. ${ }^{18}$

As I have frequently said:

People are equal and equally worth treating or saving and equality is not health status dependent. When we say all are equal we exclude discrimination on the basis of all the usual suspects: race, gender, religion, and so on. The moral principle outlawing discrimination protects (or should protect) all persons equally. People's lives and fundamental interests should be given equal weight regardless of race, creed, colour, gender, age, life expectancy or quality of life so long as that quality of life is worth having for the person whose life it is. ${ }^{19}$

It is difficult to know how I could be or could have been more explicit than this or how I could more emphatically rebut the claim that: "Put in terms of worth, Glover and Harris postulate three categories of lives: those more worth living, those less worth living; and those not worth living."

These qualifications matter because the parody Häyry offers of my views distinctly sharpens on the following page.

Glover and Harris would not kill existing people against their will, presumably because they would have sufficient respect for the subjective worth or value of their lives. But they would, in the light of their theory, prefer a world with human lives which are more rather than less worthwhile. If I could easily be replaced by a better copy, Glover and Harris would have no problem with me being lost, because they have no respect for me as an objectively separate entity. And this is exactly the logic by which they also ignore the individuality of embryos and fetuses.

I have to say that I would be sorely tempted to take Häyry at his word and replace him and his book with better copies if I could. Happily for Häyry, but less so for the plausibility of his claims about what I say or believe, I would not even consider doing it even if I could. However, the fact remains that Häyry has totally distorted what I, and I believe Glover, think and have said. Again, readers must judge whether these claims of Häyry's on such a fundamental and controversial a set of issues are the words or actions of someone who sincerely abjures confrontation. I, on the other hand, feel I have to confront such a serious misrepresentation of my views.

There is no reason for Häyry to have to resort to "presume" 20 anything, because I have set out my theory of personhood and the elements of it that explain why it is normally wrong to kill innocent people against their will, and these reasons are not subjective in any degree whatsoever. They derive from objective, that is, publicly observable and discoverable, capacities that are possessed by all individuals who have what is sometimes called "a right to life," but which I usually say are features that make life valuable in the sense that we have strong moral reasons to save or preserve that life, if we can, and equally strong reasons not to end such a life deliberately. ${ }^{21}$ These features are not only observable but there are reliable and accepted methods of testing for them even when they are not self-evident. The features to which I refer are those that permit 
self-consciousness, such as the ability of an individual, in John Locke's famous words, "to consider itself the same thinking thing in different times and places." $^{\prime 2}$ To translate this, it is the ability to possess and exhibit awareness of oneself as existing over time and possessing the ability to have a view about whether one wants that existence to continue or not. For any language user the test is simple to apply: you ask them if they want to go on living or not, and a simple yes or no or the gestural equivalent is objective evidence that they possess the requisite state of consciousness. Of course, there may be doubt in individual cases, just as there may be doubt about whether the evidence for any objective feature of the universe has been established in a particular case. But that doubt does not turn the objective into the subjective; rather it makes the objectivity of the claim doubtful in a particular case. I may not be able to find the evidence as to whether or not a particular painting is a genuine Vermeer; that evidence may not be known; but whether it is a Vermeer or not remains a question of fact. Either Vermeer painted it or he did not!

John Coggon (in a personal communication) has suggested that Häyry's use of "subjective" is supposed to refer to the individual's self-evaluation as contrasted with an evaluation that accords with some contradictory account of the good that Glover and I take to be objectively existent. In other words, Häyry may be using "objective" to refer to what I think is, in fact, worthwhile from a rational viewpoint and "subjective" to refer to what a person thinks himself, even if that flies in the face of the rational. Despite the temptation to accept Häyry's compliment in suggesting that what I think is worthwhile from a rational point of view is "objective," I would never (I hope!) have used such an ambiguous and selfaffirming term in such a context, not least because I believe that the individual is absolutely entitled to have her own determination of the good for herself respected.

And this is why, either way, Häyry is (fortunately) perfectly safe from me even if a better copy of him could be produced. He is manifestly a self-conscious being who has demonstrated this objectively, not least by writing his book. So not only is it not the case that I would have no problem with his being "lost," as he so elegantly puts it, I would defend his entitlement to life (and that of any copies of him that may be produced) as strongly as I would defend my own; and those who know me know there is nothing stronger than that!

And as for "And this is exactly the logic by which they also ignore the individuality of embryos and fetuses," I am not sure I even understand the charge. I have never ignored the individuality of embryos or fetuses. I think Häyry is using the term "individuality" as a surrogate for "moral status" and is trying to say that the same reasons that lead me to be sanguine about his death lead me to accept abortion and embryo experimentation. Because I am not sanguine about disposing of Häyry (except metaphorically or with argument), no extrapolation can be made to my views on embryos and fetuses. However, and for the record, I have argued ${ }^{23}$ that the "logic" that applies to embryos and fetuses is entirely different precisely because they are not persons and lack the objective feature of self-consciousness. Logic in English law (and that of any jurisdiction that permits some abortions but no murders) is also relatedly different.

It may, of course, be that Häyry could show that my theory of personhood is subjective and not objective, but this would take some attempt at an argument on his part.

Häyry concludes this section as follows: 
But with the division (of lives into three rather vague categories) introduced by Glover and assumed by Harris, the conclusion can be manipulated to match our predetermined views. If we do not want to condone the birth of individuals with a specific congenital ailment, we simply define this ailment as making their lives not worth living, and no further calculations are needed. This I would like to argue, is not consequentialism in its purest form. ${ }^{24}$

Note first that what was originally described as "Glover and Harris postulate three categories of lives [my emphasis]" has now been weakened to "introduced by Glover and assumed by Harris [my emphasis]." It looks as though Häyry has at some point realized that I have never used these categories in the way that he requires.

The implication of this passage is that unscrupulous people like Glover and Harris have set things up so that they can simply define any ailment as severe enough to make life not worth living and, on the basis of this, justify either abortion or embryo selection to avoid the birth. However, my theory of the value of life does not require either abortion or embryo selection to be justified on any grounds other than the moral status of the embryo or fetus, and certainly, for me, disability or "ailment" does not add one jot to the justification for embryo selection or abortion. In other words, for me, the legitimacy of abortion or embryo selection or indeed research on embryos does not depend in any way on those embryos or fetuses having any ailment whatsoever, congenital or not! And because, for me, neither embryos nor fetuses have lives the ending of which requires justification, other than in terms of their moral status (shared by all embryos and fetuses), no calculations of any sort are called for. So that so far from "no further calculations" being needed, following some labeling exercise, no calculations are needed at all, nor indeed is any labeling exercise. To be plain, for me, the quality of potential life, or disease state, of embryos plays no part in the justification for selecting against them or ending their existence. This is for the simple, and for me sufficient, reason that they will never live to experience the bad effects of that life or that disease state. We have no more responsibility for selecting against them or ending their existence than we do for failing to conceive an embryo that will expectedly have a good life. If, on the other hand, we choose to keep them alive, then we do have a responsibility for the foreseeable state in which they are likely to live. ${ }^{25}$

Finally, there is what I take to be a suggestion that I am inconsistent because I have occupied a position which is "not consequentialism in its purest form" ... Ouch! Well, I do not claim to be a consequentialist, pure or impure, although I sometimes admit to that charge when leveled against some of my arguments. ${ }^{26}$ This is a label applied to me by Häyry and others, and if I do not conform to their stereotypes of what a consequentialist should be, that is nothing to me!

Häyry concludes:

I see two main question marks in the model advocated by Glover and Harris. The first is their division of life's worth or value into three levels of "more," "less," and "none." ... My second problem with the model is its tendency to see opposing views as irrational. All appeals to prevailing norms and values, be they grounded on religion, local custom, or people's actual beliefs, are dismissed as going against reason-unless they happen to support the ideas championed by Glover and Harris, in which case they go unquestioned. ${ }^{27}$ 
I have dealt with the first question mark. For the rest, in my approach to ethics I have identified a number of very general principles that I believe recommend themselves to reason not least because they appeal to justice or to prudential selfinterest or to the protection and promotion of the lives, liberty, welfare, and flourishing of all persons. There are good reasons to prioritize all these values and in showing how they are promoted or frustrated by any act or omission, policy program, or practice. I have tried, throughout both my philosophical work and my contributions to, or interventions in, public policy and public affairs more generally, to promote these values using a combination of evidence and argument, in short by using reason. I defend the views I hold because they recommend themselves to reason and because they promote the values I hold and have just identified. In criticizing opposing views I always try to show why they are not supported by evidence or argument or are not thereby adequately supported. I do not think those who disagree with me are irrational. I do not think, or have ever implied, that they are irrational in an existential sense-that they have no reason or have poor powers of reasoning. I criticize what I perceive to be flaws in the principles they espouse or with the evidence or arguments they produce to support what they say or because they produce neither evidence nor argument in support of them.

It is unworthy of Häyry to suggest that either Glover or I dismiss ideas of others unless they happen to agree with us (is this suggestion of Häyry's confrontational? $)^{28}$ We disagree with them because we have found reason to believe that they may be wrong. When we give these reasons, this is not as an attempt to dismiss or suppress their views, but always as a challenge for these views to be justified and our own contrary or divergent views to be shown to be flawed.

One further but fundamental disagreement that I do have with Häyry's general approach is that he believes there are different kinds of rationality. There are not. There are many different ways of being rational and many different forms of argument and of considerations that may count as evidence. To understand these, or as many of them as possible, is a lifetime activity. The next challenge is to use the tools available to the mind to enable us, for example, to suit means to ends and to find ways of testing hypotheses and of evaluating arguments, in short of acting rationally. This is not the place for a more thorough discussion of rationality. Häyry is right that no one has a monopoly of rationality or privileged access to rational processes, but none of his protagonists have, I believe, claimed otherwise.

Häyry is an excellent philosopher who has produced and continues to produce work of the first quality. We do have fundamental disagreements, not least in style and also in methodology. But we also have many points of agreement. He is a courteous and stimulating philosopher with whom to engage. His book is decidedly worth reading and contains some superb insights. I cannot forebear to cite, with pleasure and admiration, at least one:

Parity of reasoning arguments polish the rails leading from one normative position to another, but where the train ends up depends on the direction in which our moral intuitions steer it. ${ }^{29}$

I would have substituted the heavenly twins "evidence and argument" for his "moral intuitions," but the thought is admirably memorable and apposite.

Finally, I hope the arguments of my contribution to this exchange are robust. That is, I hope my arguments are minimally flawed and minimally vulnerable to 
objections. This hope (perhaps ambitious) is one I am sure Häyry and I share about our respective work. But I also hope this paper has been robust in another sense, a sense to which I aspire in everything I write; that is, I hope it is clear, strong, forthright, and forcefully expressed. This is because I believe that the purpose of philosophy is not just to understand the world but to change it. ${ }^{30}$ Of course I believe that change should be change for the better, which is why I have written so frequently and over such a long period about human enhancement. To argue for, and hence to advocate, change for the better and to attempt to discover what constitutes such change is, I strongly believe, one of the fundamental purposes of, and justifications for, philosophy and indeed for science. Socrates and Plato understood this, as did Hobbes, Bentham, Mill, Marx, Russell, and Jonathan Glover. All were in some sense confrontational philosophers, and I am not ashamed of following, albeit at some considerable distance, their inspiring example. This sort of robustness may well be appropriately characterized as confrontational; I make no apology for that. The fact that I adopt a robust approach may be as much a matter of personal style as it is of devotion to methodology. Those I most admire seem to have this quality, but that is simply a biographical remark about me. Very often, however, style is also important in the persuasiveness of an argument and hence is a rhetorical device often as potent as the syllogism. Many will prefer Häyry's avowedly nonconfrontational credentials to my more direct approach on that ground alone. Both Häyry and I will, I hope, want them to go behind the style to the content. Hence this exchange.

\section{Notes}

1. Coggon J. Confrontations in "genethics": Rationalities, challenges, and methodological responses. Cambridge Quarterly of Healthcare Ethics 2011;20(1):46-55.

2. The Shorter Oxford English Dictionary Third Edition. Oxford: Oxford University Press; 1968.

3. The word safe, of course, can only mean safe enough, the degree of risk being relative to the quantum of benefit.

4. Häyry M. Rationality and the Genetic Challenge: Making People Better? Cambridge, UK: Cambridge University Press; 2010:41.

5. See note 4, Häyry 2010:40.

6. See note 4, Häyry 2010:238

7. See note 4, Häyry 2010:31. Here Häyry attributes a view to Jonathan Glover and me (which I believe neither of us holds). He then says complainingly, "This, I would like to argue, is not consequentialism in its purest form" as if (a) we are committed to consequentialism in that form and (b) we are committed to the view he ascribes to us!

8. See, for example, Häyry's attribution to me, without any evidence or citation, of a range of things I have never said. See note 4, Häyry 2010:31, para 2 (discussed in more detail below).

9. See note 4, Häyry 2010:31, note 36 .

10. See note 8 .

11. See note 4, Häyry 2010:29-39.

12. Harris J. Wonderwoman and Superman. Oxford: Oxford University Press; 1992.

13. See Harris J. Enhancing Evolution. Princeton and Oxford: Princeton University Press; 2007:168ff, and Harris J. The Value of Life. London: Routledge \& Kegan Paul; 1985:10-27, 134, and 162.

14. Cook P. Tragically I Was an Only Twin. Cook W, ed. London: Arrow Books; 1993:101.

15. See note 4, Häyry 2010:30.

16. See also Harris J. The concept of the Person and the value of life. Kennedy Institute of Ethics Journal 1999;9(4):293-308.

17. Because when infants acquire personhood is essentially an empirical and hence objective matter on my theory, there will be some uncertainty in individual cases.

18. See note 16, Harris 1999. 


\section{The Challenge of Nonconfrontational Ethics}

19. Harris J. It's not NICE to discriminate. Journal of Medical Ethics 2005;31(7):373-5. See also Harris J. Resource allocation, victims of circumstance. In: Singer P, Kuhse H, eds. A Companion to Bioethics, 2nd ed., Oxford: Basil Blackwell; 2009:374.

20. Indeed, Häyry himself knows that there is no reason for any such presumption because he states on page 214 of his book that "for Harris the point of our existence-its 'meaning' —is to lead worthwhile lives; and anything that interrupts this against our own wishes is bad."

21. See note 13, Harris 2007, note 13, Harris 1985, and note 16, Harris 1999.

22. Locke J. An Essay Concerning Human Understanding. London: Oxford University Press; 1964:bk II, p. 188.

23. See note 13, Harris 2007, and note 13, Harris 1985.

24. See note 4, Häyry 2010:31.

25. I do not suppose that this brief summary of my position on the moral status of embryos or fetuses is set out in sufficient detail to be convincing. For that, please see my The Value of Life (see note 13). I merely summarize the argument here to show that, valid or not, it is not what Häyry thinks it is.

26. Although I do, like almost every other theorist, use consequentialist arguments, and in my own case, admittedly somewhat frequently.

27. See note 4, Häyry 2010:40.

28. "Was this ambition?" See Shakespeare's Julius Caesar for the irony of this note and this quote!

29. See note 4, Häyry 2010:225.

30. See my espousal of Marx's famous remark from Theses on Fuerbach, No XI, in Feuer LS, ed. Marx and Engels. London: Collins Fontana; 1972, cited in my Wonderwoman and Superman, note 12, p. 162. 